\title{
Multiple Myeloma and Dentistry
}

\author{
Ajaz Shah, Suhail Latoo and Irshad Ahmad \\ Govt. Dental College Srinagar, University of Kashmir, \\ India
}

\section{Introduction}

Multiple myeloma (MM) is a malignant neoplasm of plasma cells that is characterized by the production of pathologic $\mathrm{M}$ proteins, bone lesions, kidney disease, hyperviscosity, and hypercalcemia. MM occurs more frequently in patients between 50 and 80 years of age, with a mean age of 60 years and man are more affected than women (1). Systemic symptoms are due to bone pain pathologic fractures, renal failure, hypercalcemia, weight loss, fatigue, weakness, fever, thrombocytopenia, neutropenia, diarrhea, orthostatic hypotension and infections $(2,3)$. Initial findings are bone pain in $68 \%$ of patients, anemia in $62 \%$, renal insufficiency in 55\%, hypercalcemia in $30 \%$, hepatomegaly in $21 \%$, and splenomegaly in $5 \%$. (4)

\section{Oral and maxillofacial manifestations}

Oral and maxillofacial lesions in patients with multiple myeloma are not uncommon, but multiple myeloma is often overlooked. Because the symptoms are many, the disease proves difficult to diagnose. Approximately 5 to $30 \%$ of myeloma patients have lesions in the jaw. Incidental discovery of lesions in the jaw may be the first evidence of this disease. Although uncommon, an initial presentation of multiple myeloma may reveal oral or maxillofacial symptoms. The oral manifestations of MM are the first sign of the disease in about $14 \%$ of the patients. (5)

The patient may experience pain, swelling, numbness of the jaws, epulis formation, or unexplained mobility of the teeth. $(6-11)$

More than $30 \%$ of patients with MM develop osteolytic lesions in the jaw (9). Osteolytic lesions are more frequent in the mandible than in the maxilla, especially in the posterior teeth region, ramus and condylar process, presumably because of greater hematopoietic activity in these areas. $(6,7)$ The radiographic appearance of the lesions is generally punched out osteolytic lesions $(60 \%)$. In most instances, the lesions appear unassociated with the apices of the teeth. $(6,12)$ (Figure 1) From the radiological point of view, MM can exhibit three distinct radiographic aspects in the skeletal system, including, in the maxillaries (9):

1. Bone with no apparent alteration

2. Multiple radiolucent areas

3. Generalized bone rarefaction

4. Osteoporotic alterations 

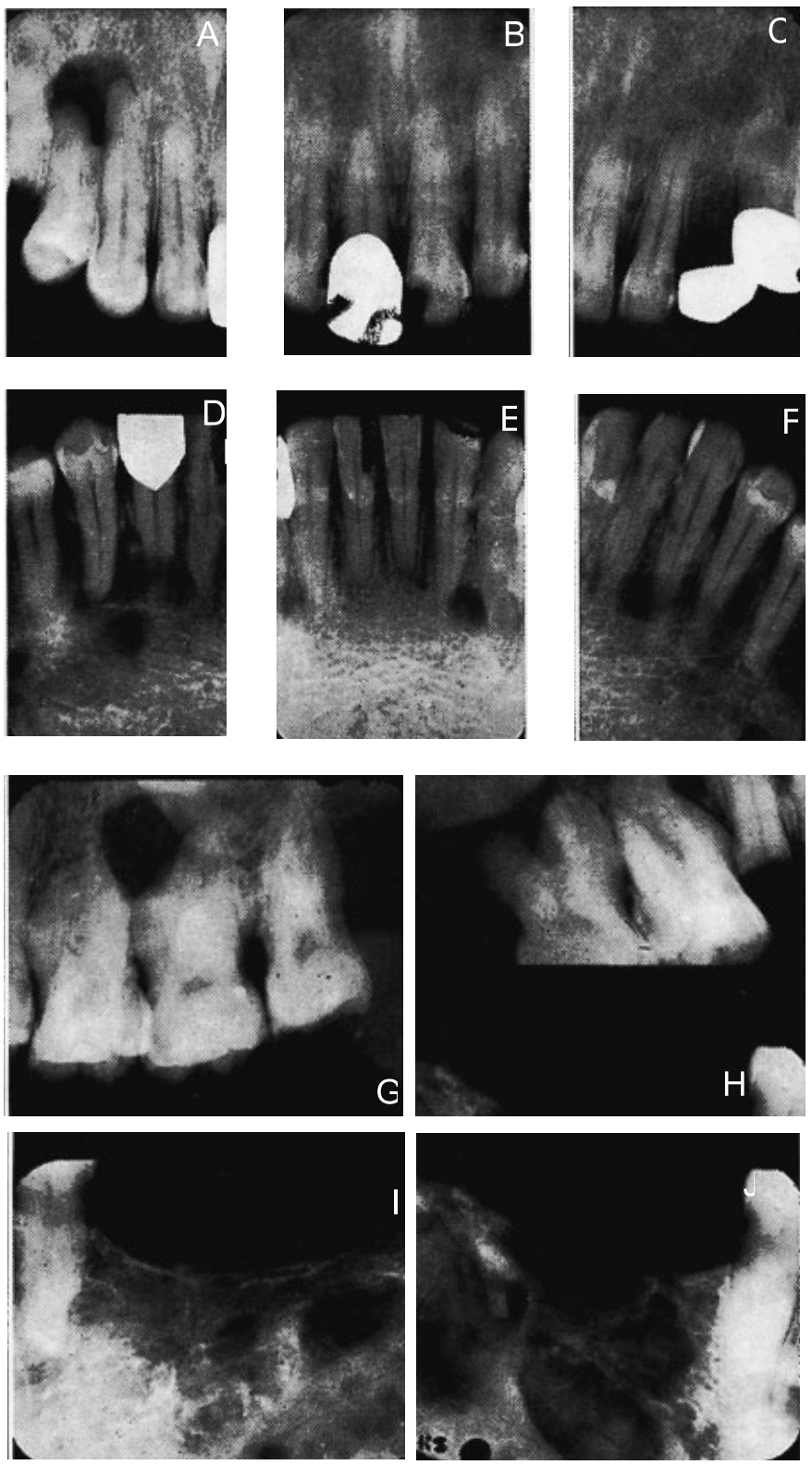

Fig. 1. Radiographs showing osteolytic lesions caused by MM in different regions of maxilla and mandible.

Skull lesions are more common than jaw lesions. Multiple radiolucent lesions of varying size, with ill-defined margins and a lack of circumferential osteosclerotic activity, should suggest this diagnosis (Figure 2). (6) 


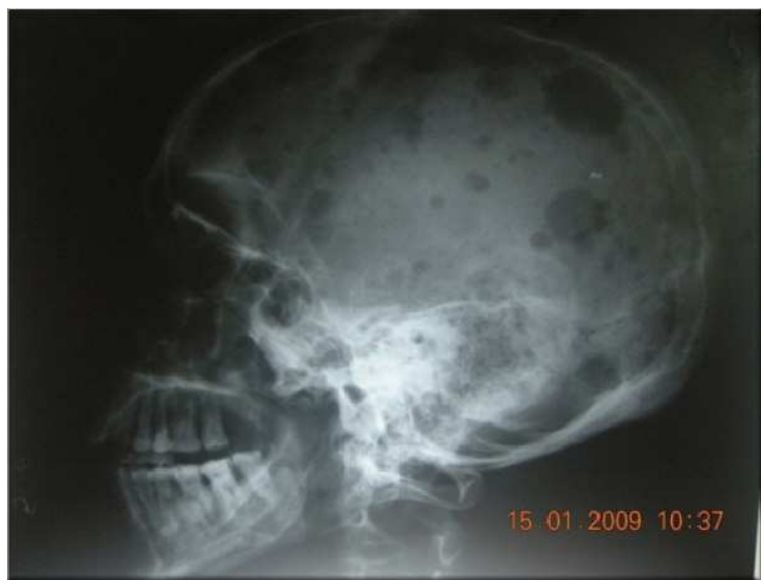

Fig. 2. Lateral Skull view showing multiple punched out radiolucent lesion

Extraosseous lesions also occur in a significant number of patients (Figure 3) although a majority of the lesions are asymptomatic.
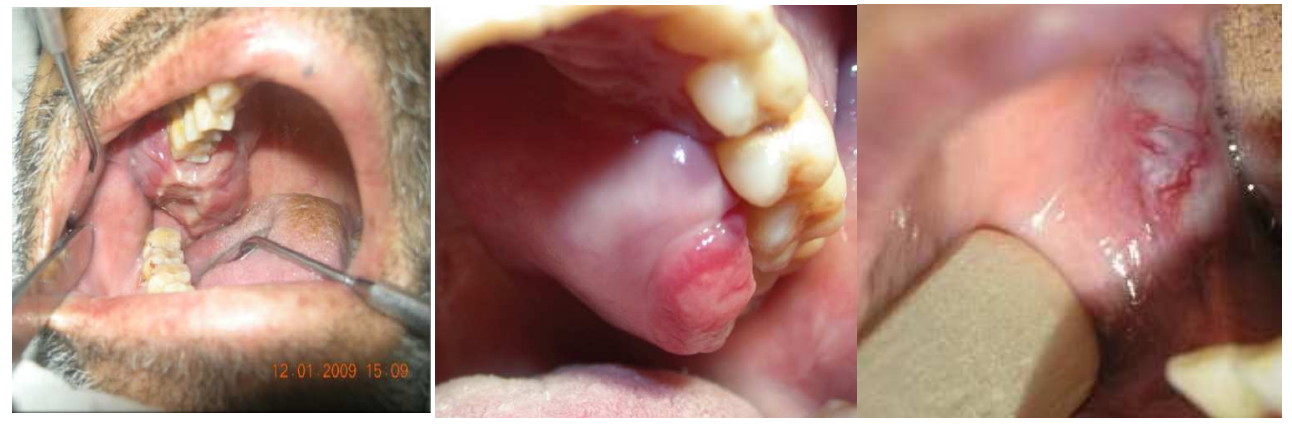

Fig. 3. Extraosseous presentations of MM

Amyloidosis as an additional complication has been reported in $6 \%$ to $15 \%$ of patients with multiple myeloma. Oral manifestations occur in nearly $39 \%$ of primary amyloidosis patients in which multiple myeloma associated lesions consist a small portion (13-15). Rarely oral amyloidosis may be the first symptom of multiple myeloma (16-18). The amyloid deposits in oral mucosa of primary amyloidosis patients presents as papules, nodules and plaques(1315,19). These lesions may interfere with speech, chewing, swallowing and ability to close mouth. Amyloid involvement of oral tissue is rather rare, and the tongue is the most encountered subsite (20). Macroglossia, usually seen in primary amyloidosis, occurs in approximately $20 \%$ of patients $(21,22)$. It seems that almost all secondary amyloidosis originates from reactive systematic conditions (23). Even though macroglossia is known to be the most common manifestation, mucosal nodules are considered to be more specific signs indicative of amyloidosis of the tongue since tongue enlargement can also occur in the absence of amyloidosis (19). Amyloid deposition in the salivary glands may cause xerostomia. In late stages, lesions may even lead to oropharyngeal blokage (24). Presence of amyloidosis in 
multiple myeloma patients is usually associated with poor survival. The median survival time in these patients is assumed to be about 4 months and death usually occurs as a complication of amyloidosis effecting major organ systems (25). Tongue biopsy is an excellent method of diagnosis. When a dentist/dental specialist is requested to take a biopsy specimen to detect amyloidosis, the specimen must include muscle tissue from the mucobuccal fold or tongue.

\section{Dental management}

Patients in long-term remission can undergo dental treatment, while patients with advanced or relapsed disease with reserved prognosis should receive palliative or urgent treatment only. Dental treatment should be performed always after consultation with the specialist, as it can be modified by certain aspects of the therapy and of the disease prognosis (26).

It is very important to carry out a detailed history. This should include the diagnosis and status of the neoplasia, the nature and duration of previous and ongoing treatment, prognosis, comorbid medical conditions, current medications, past dental history, and prior history of oral and non-oral infections (27).

All patients with MM should undergo comprehensive oral and dental evaluation in which is important to (26):

1. Evaluate for presence of petechiae, ecchymosis, gingival hemorrhage, tooth mobility, tooth migration, facial pain, and/or paresthesia, indicative of local manifestations of MM.

2. Evaluate for presence of dental/periodontal disease as a risk factor for development of osteonecrosis of the jaw (ONJ) and/or bacteraemia.

3. Evaluate radiographs (panoramic and periapicals, as indicated) for evidence of osteolytic lesions (if detected, refer for further radiographic evaluation) and to determine potential risk for developing osteonecrosis of the jaw (ONJ).

Dental treatment of these patients should be performed before starting the chemo/radiotherapy, treating any teeth with pulpal and periapical pathology, periodontal abscess, pericoronaritis, gross clinical caries and periodondontal disease. In the case of patients scheduled for autologous hematopoietic cell transplant, dental treatment should be avoided during the 3 days when stem cells are mobilized and harvested to minimize contamination secondary to iatrogenic transient bacteremia (27).

The main problems in dental treatment of patients with MM are:

\section{Tendency to bleed}

Hemorrhages are the dentist's major concerns when treating a patient with MM. Bleeding may result from several causes, including thrombocytopenia, abnormal platelet function, abnormal coagulation, or hyperviscosity. Intraoral bleeding manifests as petechiae and ecchymoses, and occasionally hematoma formation. These lesions do not require treatment, and large hematomas should not be excised due to risk of hemorrhage.

For routine operative care where bleeding is not anticipated, treatment can generally be provided in even severely thrombocytopenic patients $\left(\leq 10,000 / \mathrm{mm}^{3}\right)$ without the need for transfusions.

If surgery is necessary, recent results of platelet count, bleeding time, prothrombin time, and partial thromboplastin time should be obtained. Depending on the extent of surgery, 
coordination of platelet transfusion the day of the procedure may be indicated, although single tooth extractions can generally be managed by an experienced clinician with localized measures even with levels as low as 15,000 cells/mL (27).

\section{Increased risk of infection}

Patients with compromised lymphocyte function or low neutrophil count due to their malignancy or secondary to myelosuppressive chemotherapy are prone to newly acquired infections and/or exacerbation or reactivation of latent infections (27-29). In many cases the clinical presentation of oral infections may be atypical compared to what would normally be expected in a healthy patient population. Use of diagnostic tools, including cultures, cytological smears, and tissue biopsies, is critical in identifying pathogens and guiding appropriate therapies (27).

a. Dental infections:

Oral prophylaxis, oral hygiene instruction and elimination of oral sources of infection before beginning cancer treatment, can significantly reduce the risk of infectious complications $(27,29)$. Odontogenic infections of pulpal and periodontal origin are frequently encountered and should be suspected in the presence of orofacial pain, large restorations, gross clinical caries, and periapical radiolucency. Dental radiographs must be obtained for any suspected odontogenic infection. Endodontically treated teeth with a radiographically adequate seal can become symptomatic during severe neutropenia, and while these may be initially managed with antibiotics, in most cases extraction is indicated. Similarly, chronic periodontal disease can become acutely exacerbated with or without the traditional clinical signs of inflammation and swelling. Treatment includes broad-spectrum antibiotics, chlorhexidine rinses, scaling and curettage, and extraction of hopeless teeth. Extractions should be performed as early as possible prior to beginning therapy to allow maximum healing. Prior to extractions or any other invasive procedures the platelet and absolute neutrophils counts must be reviewed and appropriate measures taken to minimize risk of complications (27).

b. Opportunistic infections:

i. Viral infections: Primary infection or reactivation of herpes family viruses is common in these patients, especially during intensive chemotherapy and in the context of advanced disease. Herpex simplex virus is the most common viral infection in these patients and typically presents as single or multiple painful ulcerative lesions that may involve any oral mucosal surface. Varicella-zoster virus (VZV) reactivation is less common. Treatments for both infections include acyclovir, valacyclovir or famciclovir, the latter appearing to have an advantage in preventing post-herpetic neuralgia following VZV infections $(27,29)$.

ii. Fungal infections: Oropharingeal candidiasis is the most common fungal infection in cancer patients. Candidiasis can present as pseudomembranous (the most common), erythematous, hyperplastic, or angular cheilitis. Symptoms include generalized discomfort, dysgeusia, xerostomia, and burning. Initial episodes can be treated with topical azoles or nystatin for 7 to 14 days; in severe cases, systemic therapy should be considered with 100 to $200 \mathrm{mg}$ /day of fluconazole or itraconazole for 7 to 14 days or long-term for prophylaxis, especially in recurrent cases. In patients with nonhealing solitary ulcerations, deep fungal infections (aspergillus, zygomyces, and histoplasma) 
should be considered, the management of which requires aggressive therapy with intravenous azoles, amphotericin B, and the echinocandins $(27,29)$.

\section{Risk of developing osteonecrosis of jaws (ONJ)}

In MM patients treated with radiotherapy or intravenous bisphosphonates there is a risk of developing osteonecrosis of jaws. The unique environment of the oral cavity could explain why the maxilla and mandible are solely involved. It can be hypothesized that patients who have received long-term bisphosphonate therapy may have a compromised blood supply to their maxilla and mandible. When dental extractions are performed on this group of patients, the open bony wound with a compromised healing ability cannot cope with the presence of oral microflora.The extraction wound then becomes infected and progresses into osteomyelitis due to the poor healing ability of the tissues. It then develops into osteonecrosis. It should be noted that all other bones in the skeleton are well enclosed in the soft tissue and thus protected from a resident microflora. (30)

\section{Preventive recommendations}

A comprehensive recent medical history is essential before commencing any dental treatment. Identifying the risk factors in the medical history is mandatory and will help the patient's overall well-being and safety. Patients taking radiotherapy or potent bisphosphonates for more than one year, particularly for bone conditions other than osteoporosis, and those on concomitant steroids appear to be at highest risk of developing ONJ. Other factors that appear to further increase the risks include: residual multiple myeloma or another malignancy; hypoproteinemia; renal impairment from disease or drugs; and/or chemotherapy.

The treatment plan for a patient who has been on radiotherapy or bisphosphonate therapy should involve restorative dentistry, limited non-surgical periodontics and endodontics to control dental decay, periodontal disease and periapical inflammation. Patients who have dentures should have well maintained soft liners to minimize trauma to the oral mucosa or leave their dentures out. Failing soft liners would be more irritating than a hard but smooth denture.

Extraction and all types of surgery should be avoided. If an extraction is mandatory, for example an infected vertically split tooth, then the tooth should be extracted with minimal bony damage or exposure. Although there is no research to validate it, prophylactic antibiotics and suturing the socket to close the wound are advised. As a novel approach the authors have been using orthodontic elastic bands to exfoliate teeth. This results in a slow extraction over a few weeks which allows the oral mucosa to migrate down the tooth as it exfoliates so there is no open wound. $(31,32)$

There are conflicting reports regarding dental implants. Experimental studies show a positive effect of bisphosphonates on the bone around implants in experimental animals and humans $(33,3435)$. Failure of osteintegration in a patient who had successfully integrated implants but then commenced on bisphosphonate therapy has been reported.(36) Current advice is that placement of implants is best avoided if the patient has serious bone disease and are on potent doses. Osteoporotic patients on lower doses need a full informed consent before proceeding. Patients on bisphosphonate therapy with existing implants $\downarrow$ should be regularly clinically and radiographically monitored. Increased bone density around the implant, similar to that shown around the socket in may occur. If bone pain or loss of integrity occurs the superstructure should be removed and the implant left submerged.(36) 
Bone surgery must be avoided as the bone is exceedingly dense and avascular necrosis may occur.

Full dental assessment and treatment planning should occur prior to the patient commencing radiotherapy or bisphosphonate therapy (Table 1). (37)

Prior to radiotherapy/ bisphosphonate therapy

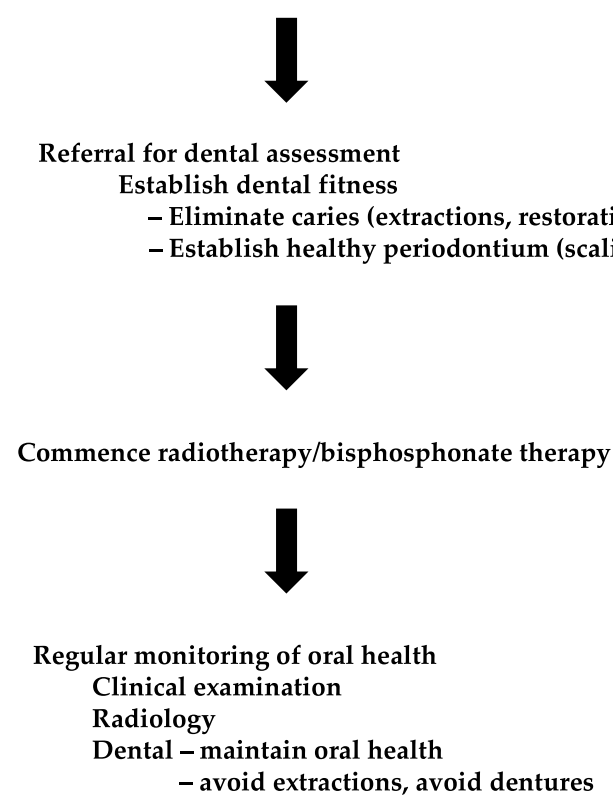

Table 1. Preventive strategy for OJN

\section{Therapeutic recommendations}

The first step is to establish the diagnosis if a patient on radiotherapy/bisphosphonate therapy presents with a non-healing oral wound. This requires an accurate medical and dental history. Patients with diabetes and immunocompromised patients can have delayed wound healing. Once the diagnosis of $\mathrm{ONJ}$ is made the treating medical practitioner, oral and maxillofacial surgeon and dentist need to confer to establish a management plan. At present there is no simple single effective treatment for ONJ. (38-42)

The first approach should be non-surgical with the use of antiseptic mouth rinses and antibiotics to prevent or treat secondary infection. Removable appliances lined with a periodontal pack that passively cover the bony defect can be inserted to protect the site from further trauma and may aid mucosal covering of the exposed bone. $(37,42)$

If the exposed bone is painful or there is significant secondary infection, localized surgical debridement without primary reconstruction can be considered. Minimal mucoperiosteal flap reflection to preserve the blood supply to underlying bone should be used. The problem is that the whole skeleton is involved. Resection to a normal bleeding bone margin cannot be 
undertaken as for osteoradionecrosis. Bone grafting, either as a free graft or by microvascular transfer, involves affected bone. There is a risk that there could be two problem areas, the donor graft site as well as the recipient jaw site. Major re-section surgery should be avoided if at all possible. (38-42)

In summary, for established cases it is recommended that treatments begin with the recognition that palliation and control of secondary infection are the primary goals. Control of progression has been obtained in most cases with long-term or intermittent courses of a penicillin or second generation cephalosporin, chlorhexidine mouthwash and periodic minor debridement of soft-textured sequestrating bone and wound irrigation (Table 2).

Ensure correct diagnosis

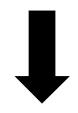

Cease Radiotherapy/bisphosphonate if possible

NB: Minimum 3 month duration before surgical intervention*

- Antibiotics if secondary infection (penicillin, cephalosporin or clindamycin)

- Antiseptic mouthwash (e.g., Chlorhexidine gluconate)

- Cover with periodontal pack

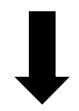

Surgical debridement
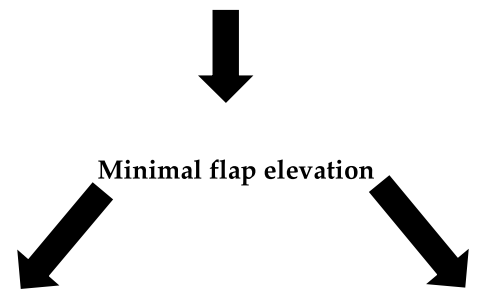

Resolution

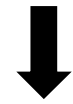

Consider bisphosphonate therapy without primary reconstruction
Non-resolution

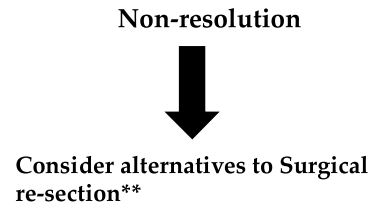
re-section**

*It is probable that this time span is too short.

${ }^{* *}$ Extreme caution is recommended at this point

Table 2. Therapeutic management of ONJ

\section{Anemia}

Patients with severe anemia often complain of that they fatigue easily and may not be able to tolerate time-consuming dental treatment. 

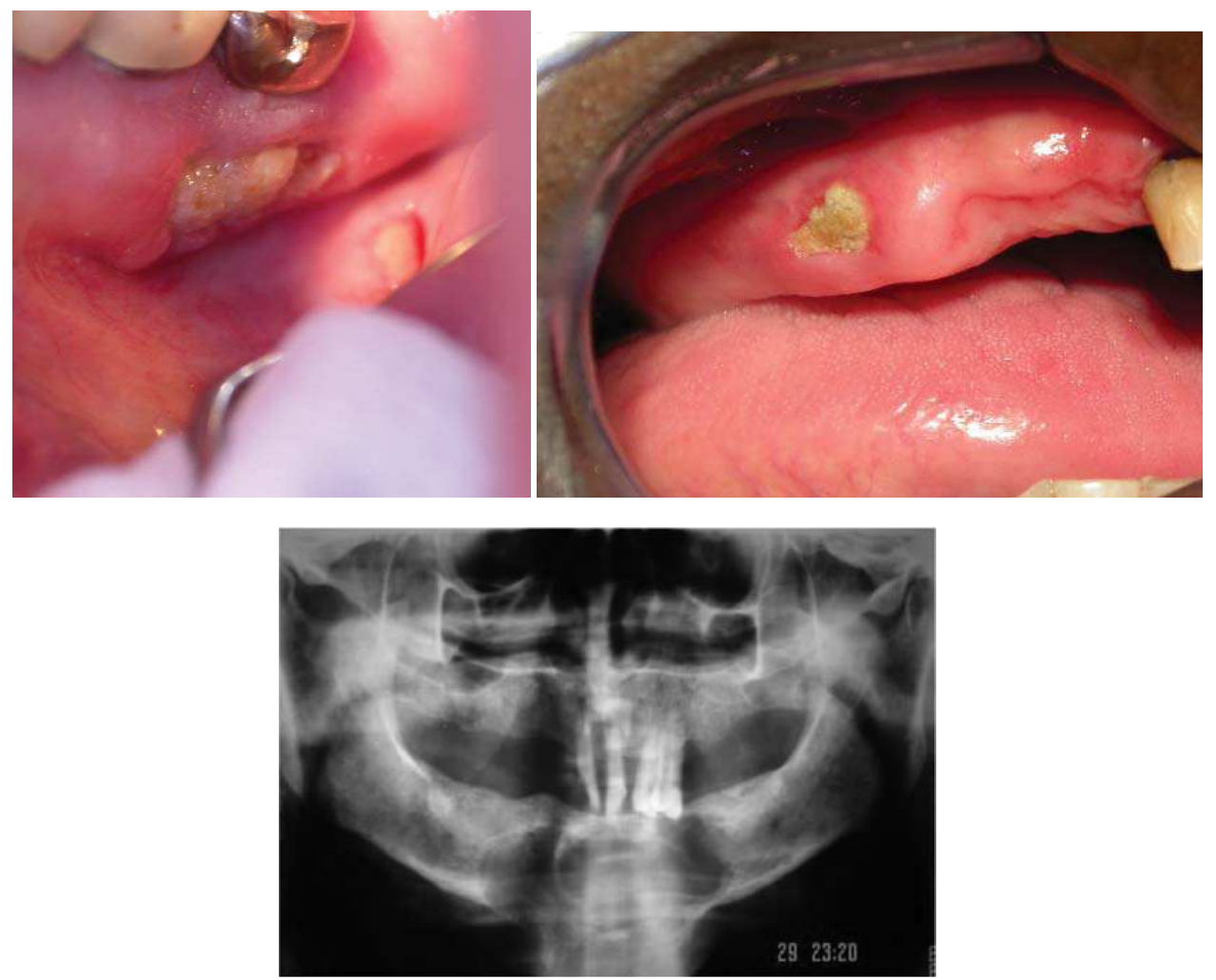

Fig. 4. Clinical and radiographic presentations of ONJ

The need for blood products and the appropriate venue for dental treatment should be discussed with the patient's oncologist, as these patients may require continuous monitoring of vital signs and blood counts perioperatively (26).

\section{Corticosteroids treatment}

Patients receiving high-dose systemic corticosteroids may display evidence of secondary adrenal insufficiency. Adrenal crises secondary to insufficiency are rare in the dental setting, and steroid supplementation before nonsurgical dental procedures is not recommended. Steroid supplementation before oral surgery is usually recommended. The amount, duration, and venue for supplementation should be determined by both the dental specialist performing the procedure and the patient's oncologist (26).

\section{Secondary malignancy}

Patients treated for MM are at high risk for relapse of primary disease as well as developing secondary malignancies. Considering the increased risk of second primary cancer of the head and neck in the survivors of MM, and the fact that squamous cell carcinoma is the most common second primary solid malignancy after allogeneic hematopoietic cell transplant, oral health care professionals play a critical role in the long-term surveillance of this patient population (27). 


\section{Specific considerations}

- Patients with renal dysfunction may require modified dosing intervals of medications (26).

- In patients with multiple myeloma, it is important to evaluate for presence of hard/soft tissue masses that could indicate deposition of plasma cells and/or light chain associated amyloid, and biopsy if necessary (26).

- Patients with multiple myeloma and significant bone pain, especially in the back, may need frequent breaks and may require frequent repositioning during dental procedures (26).

- In patients undergoing orthodontic treatment, the removal of orthodontic appliances and delivery of retainers is recommended, as well as the postponement of orthodontic treatment until the patient has finished immunosuppressive therapy and the risk of hematologic relapse requiring further intervention is reduced $(43,44)$.

Considerations in dental treatment of patients with MM are summarized in table 3.

\begin{tabular}{|c|c|}
\hline Prior to dental treatment & During dental treatment \\
\hline 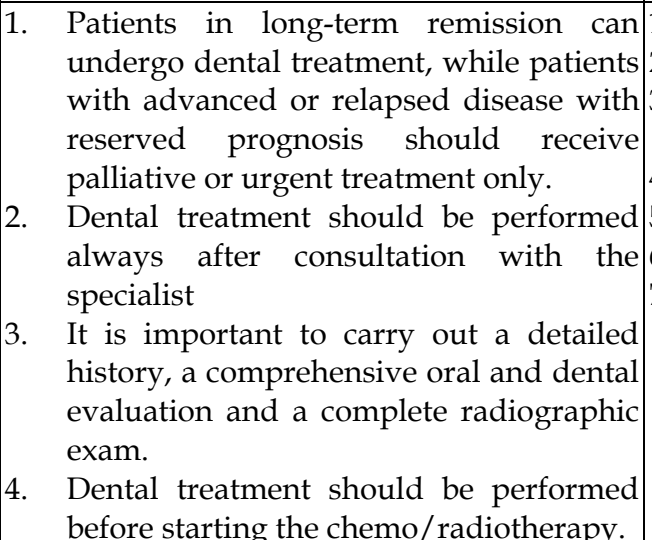 & $\begin{array}{ll}\text { 1. } & \text { Bleeding tendency } \\
\text { 2. } & \text { Increased risk of infection } \\
\text { 3. } & \text { Risk of developing osteonecrosis of the } \\
\text { 4. } & \text { Aaw. } \\
\text { 5. } & \text { Corticosteroids treatment } \\
\text { 6. } & \text { Secondary malignancies } \\
\text { 7. } & \text { Specific considerations }\end{array}$ \\
\hline
\end{tabular}

Table 3. Considerations in dental treatment of patients with MM

\section{References}

[1] Kyle RA, Gertz MA, Witzig TE, Lust JA, Lacy MQ, Dispenzieri A etal. Review of 1027 patients with newly diagnosed multiple myeloma. Mayo Clin Proc 2003; 78:21-33.

[2] Currie WJ, Hill RR, Keshani DK. An unusual cause of maxillary tuberosity enlargement. Br Dent J 1994;177:60-2.

[3] Zachriades N, Papanicolaou S, Papavassiliou D, Vairaktaris E, Triantafyllou D, Mezitis M. Plasma cell myeloma of the jaws. Int J Oral Maxillofac Surg 1987;16:510-5.

[4] Kyle RA. Multiple myeloma: review of 869 cases. Mayo Clin Proc 1975;50:29-40.

[5] Epstein JB, Voss NJ, Stevenson-Moore P. Maxillofacial manifestations of multiple myeloma. An unusual case and review of the literature. Oral Surg Oral Med Oral Pathol 1984;57:267-71. 
[6] Lee SH, Huang JJ, Pau WL, Chan CP. Gingival mass as the primary manifestation of multiple myeloma. Oral Surg Oral Med Oral Pathol 1996;82:75- 79.

[7] Lambertenghi-Deliliers G, Bruno E, Cortellezzi A, Fumagalli L, Morosini A. Incidence of jaw lesions in 193 patients with multiple myeloma. Oral Surg Oral Med Oral Pathol 1988;65:533-537.

[8] Seoane J, Aguirre-Urizar JM, Esparza-Gómez G, Suárez-Cunqueiro M, Campos-Trapero J, Pomareda M. The spectrum of plasma cell neoplasia in oral pathology. Med Oral. 2003 Aug-Oct;8(4):269-80.

[9] Epstein JB, Voss NJ, Stevenson-Moore P. Maxillofacial manifestations of multiple myeloma. An unusual case and review of the literature. Oral Surg Oral Med Oral Pathol. 1984 Mar;57(3):267-71.

[10] Mozaffari E, Mupparapu M, Otis L. Undiagnosed multiple myeloma causing extensive dental bleeding: report of a case and review. Oral Surg Oral Med Oral Pathol Oral Radiol Endod. 2002 Oct;94(4):448-53.

[11] Reboiras López MD, García García A, Antúnez López J, Blanco Carrión A, Gándara Vila P, Gándara Rey JM. Anaesthesia of the right lower hemilip as a first manifestation of multiple myeloma. Presentation of a clinical case. Med Oral. 2001 MayJul;6(3):168-72.

[12] Pinto L SS, Campagnoli EB, Leon JE, etal. Maxillary lesion presenting as a first sign of multiple myeloma. Case report.Med Oral Patol Oral Cir Bucal 2007; 12: E344-7.

[13] Reinish El, Raviv M, Srolovitz H, Gornitsky M. Tongue, primary amiloidosis and multiple myeloma. Oral Surg Oral Med Oral Pathol 1994; 77: 121-125.

[14] Jacobs P, Sellars S, King HS. Massive macroglossia, amyloidosis and myloma. Postgrad Med J 1988; 64: 696-8.

[15] Van Der Wal, Logmans SH, Van Der Kwast WAM, Van Der Vaal I. Amyloidosis of the tongue: A clinical and postmortem study. J Oral Pathol 1984; 13: 632-639.

[16] Kielts TR. Amyloidosis of the buccal mucosa as diagnostic precursor in multiple myeloma: Report of a case. J Am Dent Assoc. 1964; 69: 701.

[17] Flick WG, Lawrence FR. Oral amyloidosis as initial symptom of multiple myeloma. Oral Surg 1980; 49: 18-20.

[18] Babajews A. Occult multiple myeloma associated with amyloid of the tongue. Br J Oral Maxillofac Surg. 1985; 23: 298-303.

[19] Raubenheimer EJ, Dauth J, Pretorius FJ. Multiple myeloma and amyloidosis of the tongue. J Oral Pathol 1988; 17: 554-9.

[20] Rutger I, Martijn R, Peter C, Theo M. Amyloidosis of the tongue as a paraneoplastic marker of plasma cell dyscrasia. Oral Surg Oral Med Oral Pathol 2002;94:444-447.

[21] Smith A, Speculand B. Amyloidosis with oral involvement. Br J Oral Maxillofac Surg 1985;23:435-444.

[22] Yusa H, Yoshida H, Kikuchi H, Onizawa K. Dialysis-related amyloidosis of the tongue. J Oral Maxillofac Surg 2001;59:947-950.

[23] Mardinger O, Rotenberg L, Chaushu G, Taicher S. Surgical management of macroglossia due to primary amyloidosis. Int J Oral Maxillofac Surg 1999; 28:129131.

[24] Daoud MS, Lust JA, Kyle Ra, Pittelkow MR. Monoclonal gammopathies and associated skin disorders. J Am Acad Dermatol 1999; 40: 507-515.

[25] Salisbury PL, Jacoway RJ. Oral amyloidosis: a late complication of multiple myeloma. Oral Surg Oral Med Oral Pathol 1983; 56: 48. 
[26] Stoopler ET, Vogl DT, Stadtmauer EA. Medical management update: multiple myeloma. Oral Surg Oral Med Oral Pathol Oral Radiol Endod. 2007;103:599-609.

[27] Mawardi H, Cutler C, Treister N. Medical management update: Non-Hodgkin lymphoma. Oral Surg Oral Med Oral Pathol Oral Radiol Endod. 2009;107:e19-33.

[28] Raut A, Huryn JM, Hwang FR, Zlotolow IM. Sequelae and complications related to dental extractions in patients with hematologic malignancies and the impact on medical outcome. Oral Surg Oral Med Oral Pathol Oral Radiol Endod. 2001;92:4955.

[29] Heimdahl A. Prevention and management of oral infections in cancer patients. Support Care Cancer. 1999;7:224-8.

[30] Melo MD, Obeid G. Osteonecrosis of the maxilla in a patient with a history of bisphosphonate therapy. J Can Dent Assoc 2005;71:111-113.

[31] Lawler B, Sambrook PJ, Goss AN. Antibiotic prophylaxis for dentoalveolar surgery: is it indicated? Aust Dent J 2005;50 Suppl 2:S54-S59.

[32] Arvier J, Tideman H, Vickers P. Foreign bodies and gingival lesions. Aust Dent J 1987;32:285-287.

[33] Yoshinari M, Oda Y, Inoue T, Matsuzaka K, Shimono M. Bone response to calcium phosphate-coated and bisphosphonateimmobilized titanium implants. Biomaterials 2002;23:2879- 2885.

[34] Duarte PM, deVasconcelor Gurgel BC, Sallum AW, Filho GR, Sallum EA, Nociti FH. Alendronate therapy may be effective in the prevention of bone loss around titanium implants inserted in estrogen deficient rats. J Periodontal 2005;76:107-114.

[35] Degidi M, Piatelli A. Immediately loaded bar-connected implants with an anodized surface inserted in the anterior mandible in a patient treated with disphosphonates for osteoporosis: a case report with a 12 month follow up. Clin Implant Dent Relat Res 2003;5:269-272.

[36] Starck WJ, Epker BN. Failure of osseointegrated dental implants after disphosphonate therapy for osteoporosis: a case report. Int J Oral Maxillofac Implants 1995;10:74-78.

[37] Expert Panel Recommendations for the prevention, diagnosis and treatment of osteonecrosis of the jaws. June 2004. (Submitted for publication). Available www.novartis.com.au

[38] Ruggiero SL, Mehrotra B, Rosenberg TJ, Engroff SL. Osteonecrosis of the jaws associated with the use of bisphosphonates: a review of 63 cases. J Oral Maxillofac Surg 2004;62:527-534.

[39] Tarassoff P, Csermak K. Avascular necrosis of the jaws: risk factors in metastatic cancer patients. J Oral Maxillofac Surg 2003;61:1238-1239.

[40] Marx RE. Pamidronate (Aredia) and zoledronate (Zometa) induced avascular necrosis of the jaws: a growing epidemic. J Oral Maxillofac Surg 2003;61:1115-1117.

[41] Migliorati CA. Bisphosphonates and oral cavity avascular bone necrosis. J Clin Oncol 2003;21:4253-4254.

[42] Carter GD, Goss AN, Doecke C. Bisphosphonates and avascular necrosis of the jaw: a possible association. Med J Aust 2005;182:413-415.

[43] Sheller B, Williams B. Orthodontic management of patients with hematologic malignancies. Am J Orthod Dentofacial Orthop. 1996;109:575-80.

[44] Isaac AM, Tholouli E. Orthodontic treatment for a patient who developed acute myeloid leukemia. Am J Orthod Dentofacial Orthop. 2008;134:684-8. 


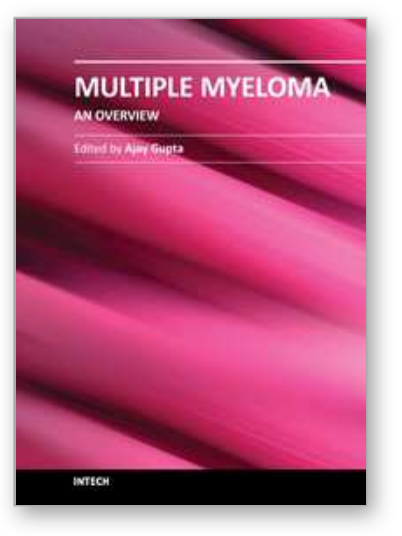

\author{
Multiple Myeloma - An Overview \\ Edited by Dr. Ajay Gupta
}

ISBN 978-953-307-768-0

Hard cover, 274 pages

Publisher InTech

Published online 20, January, 2012

Published in print edition January, 2012

Multiple myeloma is a malignant disorder characterized by the proliferation of plasma cells. Much insight has been gained into the molecular pathways that lead to myeloma and indeed much more remains to be done. The understanding of these pathways is closely linked to their therapeutic implications and is stressed upon in the initial chapters. Recently, the introduction of newer agents such as bortezomib, lenalidomide, thalidomide, liposomal doxorubicin, etc. has led to a flurry of trials aimed at testing various combinations in order to improve survival. Higher response rates observed with these agents have led to their integration into induction therapies. The role of various new therapies vis a vis transplantation has also been examined. Recent advances in the management of plasmacytomas, renal dysfunction, dentistry as well as mobilization of stem cells in the context of myeloma have also found exclusive mention. Since brevity is the soul of wit our attempt has been to present before the reader a comprehensive yet brief text on this important subject.

\title{
How to reference
}

In order to correctly reference this scholarly work, feel free to copy and paste the following:

Ajaz Shah, Suhail Latoo and Irshad Ahmad (2012). Multiple Myeloma and Dentistry, Multiple Myeloma - An Overview, Dr. Ajay Gupta (Ed.), ISBN: 978-953-307-768-0, InTech, Available from:

http://www.intechopen.com/books/multiple-myeloma-an-overview/multiple-myeloma-and-dentistry

\section{INTECH}

open science | open minds

\author{
InTech Europe \\ University Campus STeP Ri \\ Slavka Krautzeka 83/A \\ 51000 Rijeka, Croatia \\ Phone: +385 (51) 770447 \\ Fax: +385 (51) 686166 \\ www.intechopen.com
}

\author{
InTech China \\ Unit 405, Office Block, Hotel Equatorial Shanghai \\ No.65, Yan An Road (West), Shanghai, 200040, China \\ 中国上海市延安西路65号上海国际贵都大饭店办公楼 405 单元 \\ Phone: +86-21-62489820 \\ Fax: +86-21-62489821
}


(C) 2012 The Author(s). Licensee IntechOpen. This is an open access article distributed under the terms of the Creative Commons Attribution 3.0 License, which permits unrestricted use, distribution, and reproduction in any medium, provided the original work is properly cited. 